\section{SCL/Tal-1 transcription factor acts downstream of cloche to specify hematopoietic and vascular progenitors in zebrafish}

\author{
Eric C. Liao, ${ }^{1,2}$ Barry H. Paw, ${ }^{1}$ Andrew C. Oates, ${ }^{3}$ \\ Stephen J. Pratt, ${ }^{1}$ John H. Postlethwait, ${ }^{4}$ and \\ Leonard I. Zon ${ }^{1,5}$
}

\begin{abstract}
${ }^{1}$ Division of Hematology/Oncology, Children's Hospital, Department of Pediatrics and Howard Hughes Medical Institute, Harvard Medical School, Boston, M assachusetts 02115 USA; ${ }^{2}$ Division of Health Sciences and Technology, Massachusetts Institute of Technology (MIT), Cambridge, M assachusetts 02139 USA; ${ }^{3}$ Ludwig Institute for Cancer Research, PO Royal Melbourne Hospital, Victoria, Australia; ${ }^{4}$ Institute of N euroscience, University of Oregon, Eugene, Oregon 97403 USA
\end{abstract}

SCL/Tal-1 is a transcription factor necessary for hema topoietic stem cell differentiation. Although SC L is also expressed in endothelial and neural progenitors, SCL function in these cells remains unknown. In the zebrafish mutant cloche (clo), SCL expression is nearly abolished in hematopoietic and vascular tissues. Correspondingly, it was shown previously that clo fails to differentiate blood and angioblasts. Genetic analysis demonstrates that the clo mutation is not linked to the SC L locus. Forced expression of SC L in clo embryos rescues the blood and vascular defects, suggesting that SC L acts downstream of clo to specify hematopoietic and vascular differentiation.

Received N ovember 21, 1997; revised version accepted January 16, 1998.

SCL (or Tal-1) is a basic helix-loop-helix (bHLH) transcription factor identified by its involvement in chromosomal translocations or upstream deletions associated with acute lymphocytic leukemia (Begley et al. 1989; Finger et al. 1989; Chen et al. 1990). During normal devel opment the $S C L$ gene is expressed in blood precursors (Green et al. 1991), endothelial progenitors (Kallianpur et al. 1994; Drake et al. 1997), and the brain (Green et al. 1992). Targeted disruption of the SCL gene in ES cells has established an essential rol ein hematopoiesis, acting at the stem cell level to specify all blood lineages (for review, see Green 1996; Shivdasani and Orkin 1996). Because the $\mathrm{SCL}^{-1-}$ mice die during early embryogenesis, this precludes direct analysis of possible SCL function in other tissues where SCL is expressed, such as the endothelium and the brain.

[Key Words: SCL/Tal-1; clo; zebrafish; hematopoiesis; vascul ogenesis] ${ }^{5}$ Corresponding author.

E-MAIL zon@rascal.med.harvard.edu; FAX (617) 355-7262.
Previous studies demonstrate an intimate rel ationship between blood and vascular development. Throughout vertebrate ontogeny, hematopoietic and vascular tissues arise in anatomical proximity (Sabin 1920; Pardanaud et al. 1987; Pardanaud et al. 1996). Blood and endothelial progenitors coexpress some molecular markers, such as CD34, c-kit, and flk-1 (Yamaguchi et al. 1993; Bernex et al. 1996; Kabrun et al. 1997; Shalaby et al. 1997; Wood et al. 1997). Targeted disruption of some genes, such as flk-1 and CBF, result in combined vascular and hematopoietic defects (Shalaby et al. 1995; Okuda et al. 1996; Wang et al. 1996). Furthermore, a zebrafish mutant cloche (clo) affects both blood and endothelial differentiation (Stainier et al. 1995). Because of the loss of endocardium, the clo mutant has enlarged cardiac chambers evident at $26 \mathrm{hr}$ post-fertilization (hpf) (Liao et al. 1997). clo homozygotes have near undetectable expression of GATA-1 and flk-1, and complete loss of tie-1 (Liao et al. 1997). GATA-1 is a marker for differentiated red blood cells, whereas flk-1 and tie-1 are markers for endothelial cells (for review, see Mustonen and Alital o 1995; Shivdasani and Orkin 1996). These and other studies suggest that interactions between hematopoietic and vascular tissue during early embryogenesis contribute to the proper differentiation of both tissues.

Here, we identity zebrafish SCL and examine its expression in hematopoietic and vascular progenitors during zebrafish embryogenesis.

\section{Results}

$\mathrm{SCL}$ is highly conserved across vertebrate species

A zebrafish SCL CDNA was identified (SCLa2.1) by hybridization using the bHLH domain of murine and Xenopus SCL CDNAs. Conceptual translation of SCLa2.1 sequence reveals that $\mathrm{SCL}$ is highly conserved across vertebrates (Fig. 1), where the bHLH domain (amino acids 188 to 243) is identical in zebrafish, Xenopus, chick, mouse, and human. Zebrafish SCL is most homologous to the chicken peptide (36\% identity). Such high conservation of SCL among vertebrates implies a shared function during vertebrate development.

SCL expression delineates hematopoietic and endothelial progenitors

To examine patterns of SCL expression during zebrafish embryogenesis, RNA in situ analysis was carried out on whole embryos at various time points (Fig. 2). SCL transcripts are detected as early as the 1 somite stage in the anterior and posterior regions of the lateral plate mesoderm (data not shown). By 5 somites (12 hpf) SCL is expressed in the anterior (Fig. 2A), dorsal (Fig. 2B), and posterior (Fig. 2C) lateral plate mesoderm. As the embryo develops, SCL expression expands rostrally and caudally. The anterior lateral mesoderm cells contribute to form bilateral cranial vascular plexi (arrowhead, Fig. 2E); dorsal cells contribute to the dorsal aorta primordium. The posterior cells begin to fuse by 20 somites (arrowhead 


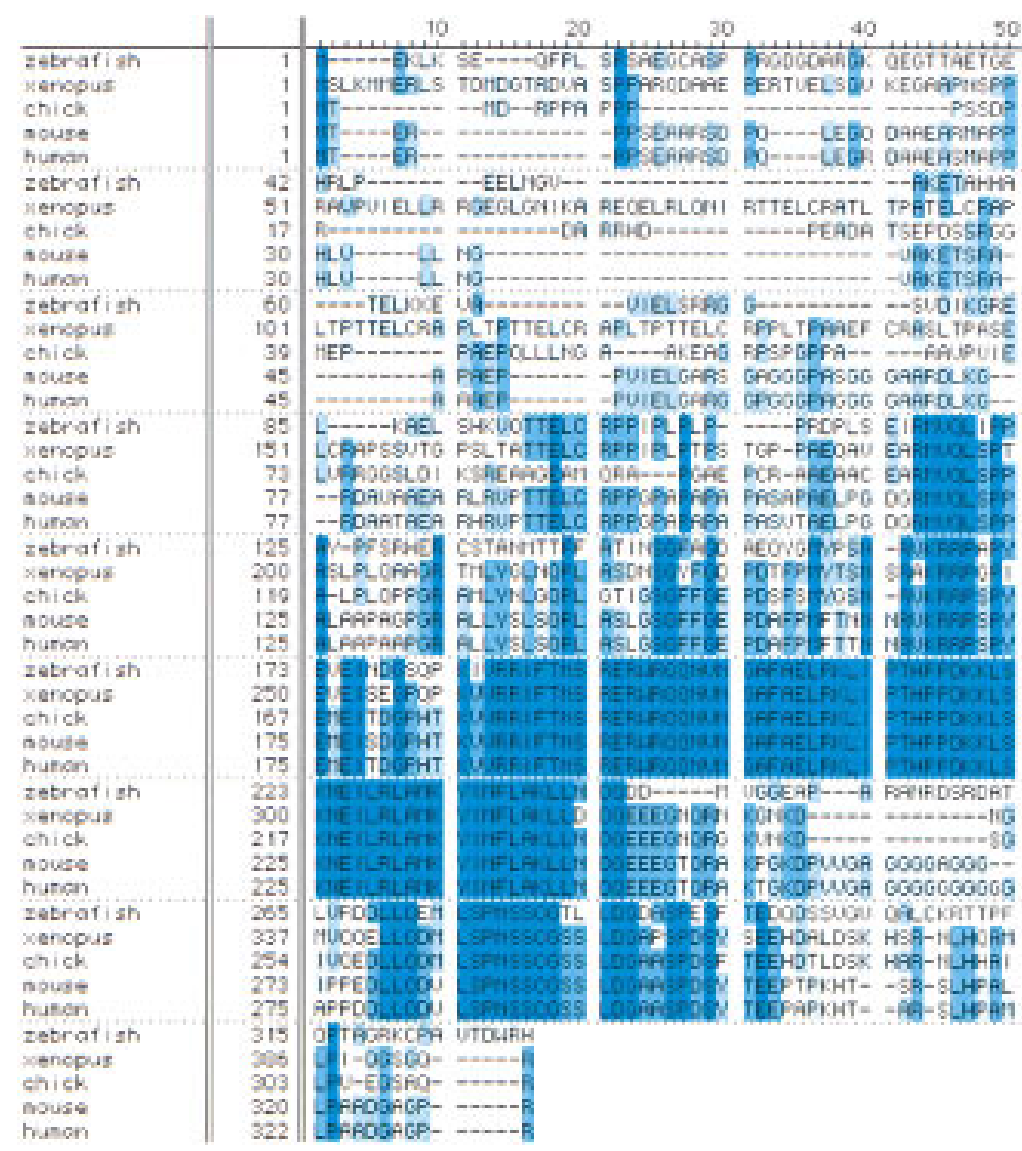

Figure 1. Zebrafish SCL peptide sequence compared with that of Xenopus, chick, mouse, and human (amino acids identical across species is in dark blue, with decreasing similarity in lighter shades). enter circulation (arrowhead with asterisk, Fig. 2l). By 2 days postfertilization (dpf), SCL expression in vascular primordia subsides and hematopoietic expression is reduced to a few circulating cells (arrowhead, Fig. 2I). By 3 dpf, SCL expression is most intense in the developing brain but can also be detected weakly in the posterior tail (arrowhead, Fig. 2J). At the same time, c-myb transcripts are detected more strongly in this posterior tail region (Fig. 2K); c-myb is associated with definitive hematopoiesis in mice (Mucenski et al. 1991). SCL expression in the posterior tail region becomes evident by $4 \mathrm{dpf}$ (Fig. 2L). Interestingly, SCL expression is al so local ized to the heart (Fig. 2L). Transverse histological section of the heart reveals that both cardiac chambers are filled with SCL-positive cells (arrowhead, Fig. 2N). SCL-positive cells are also consistently observed within the dorsal aorta (arrowhead, Fig. 2O) and axial vein (arrowhead with asterisk, Fig. 20) throughout the embryo. We suggest that these SCL-positive cells in the heart lumen represent pooled blood in the fixed day 4 embryo. However, the posterior tail SCL expression is not restricted to the vessel (Fig. 2P). Here, SCL transcripts are detected strongly in a group of cells ventral to the axial vein [ventral vein region (VVR)], bound anteriorly by the end of the pronephric duct, and posteriorly by the end of notochord. By $5 \mathrm{dpf}, \mathrm{SCL}$ expression in the VVR subsides. with asterisk, Fig. 2D) and form the intermediate cell mass (ICM) by $24 \mathrm{hpf}$ (arrowhead, Fig. 2G). The ICM contributes to both hematopoiesis and vasculogenesis (Detrich et al. 1995; Pardanaud et al. 1996).

Although SCL expression is similar to that of $\mathrm{flk}-1$ during early zebrafish development, there are two significant differences. SCL transcripts are not detected in the rostral bilateral flk-1-positive cells at 20 somites, which represent the precardiac angioblasts that form the endocardium (Stainier et al. 1993; Liao et al. 1997). Instead, a more caudal set of bilateral stripes are SCL positive, representing those lateral mesoderm cells that do not converge to form the ICM (arrowhead, Fig. 2D). These bilateral cells persist dorsally to $24 \mathrm{hpf}$ (arrowhead, Fig. 2F), and are located immediately lateral to the dorsal aorta primordium. Furthermore, SCL expression in the ICM differs from that of GATA-1 (Detrich et al. 1995). Although both SCL and GATA-1 transcripts are detected at high levels in the ICM, SCL expression extends more posteriorly (arrowhead, Fig. 2G).

As circulation commences $\sim 26 \mathrm{hpf}, \mathrm{SCL}$-positive blood cells begin to leave the ICM and enter the primitive vascular network. Circulating blood is evident in the cardinal vein (arrowhead, Fig. $2 \mathrm{H}$ ). However, it is not clear whether the blood progenitors in the posterior ICM
The zebrafish clo mutation abrogates SCL expression RN A in situ analysis in the clo mutant reveal s that SCL expression is abrogated in the lateral plate mesoderm at 5-somites (Fig. 3A). By 24 hpf, SCL transcripts are detected in the hindbrain and spinal neurons (Fig. 3B). However, the clo mutant fails to express SCL in any of the angioblast populations described previously (cf. Fig. 3B with Fig. 2, E, F, and G). Previous work suggests that most endothelial cells are deleted by the clo mutation, where only a small population in the posterior tail is spared (Stainier et al. 1995; Liao et al. 1997). Moreover, the hematopoietic progenitors fail to form in the embryo. At $24 \mathrm{hpf}$, very few cells (5-10) with SCL transcripts can be detected in the ICM (arrow, Figure 3B). These rare hematopoietic precursors can differentiate and give rise to a very small number of GATA-1-positive cells, which remain in the tail (Liao et al. 1997). These GATA-1-positive blood cells persist into $36 \mathrm{hpf}$ (data not shown) but are not detected with GATA-1 (Fig. 4) or SCL (Fig. $3 C$ ) in situ later at $2 \mathrm{dpf}$. SCL expression in the developing brain appears unperturbed by clo.

Because SCL expression is severely affected by the clo defect, it was important to ascertain whether the SCL locus represents the cl o mutation. A singl e-strand length polymorphism (SSLP) was defined in the SCL CDNA. In- 
A
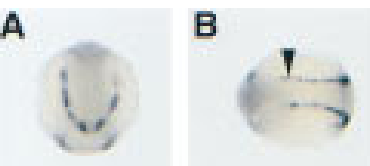

C

E

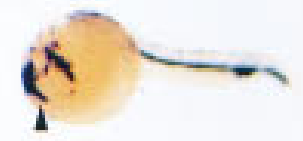

$\mathrm{H}$

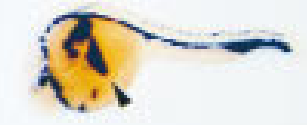

$J$

L
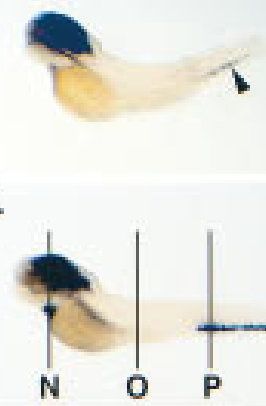

(1)

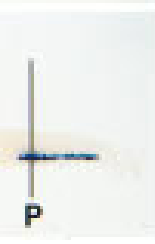

M
$\mathrm{F}$

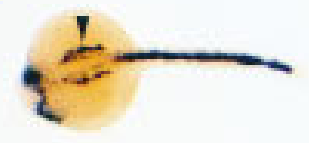

1

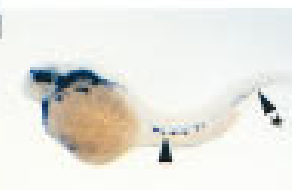

$\mathrm{K}$

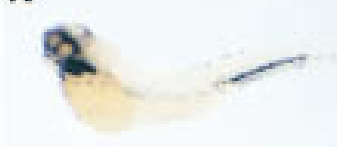

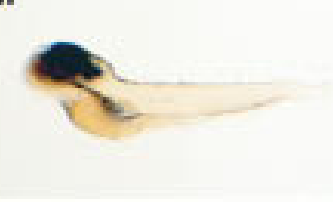

G
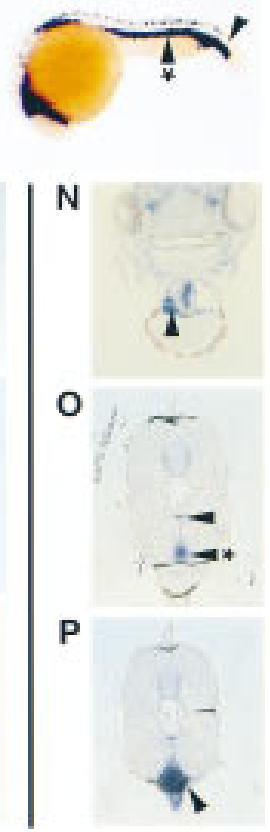

Figure 2. $S C L$ expression in vascular and hematopoietic progenitors during early development. SCL RNA in situ hybridization at 5-somites stage (A-C), 18-somites stage (D), $24 \mathrm{hpf}(\mathrm{E}-\mathrm{G}), 26 \mathrm{hpf}(\mathrm{H}), 2 \mathrm{dpf}(\mathrm{I}), 3 \mathrm{dpf}(\mathrm{)}), 4 \mathrm{dpf}(\mathrm{K}, \mathrm{L})$, and $5 \mathrm{dpf}(\mathrm{M})$. T ransverse histological sections $(6 \mu \mathrm{m})$ from $4 \mathrm{dpf}$ embryos are shown in N-P, corresponding to labeled lines in L. All are in situs done with $S C L$, except $K$, which is with c-myb. All are viewed laterally, with anterior to the left and dorsal up, except A which is an anterior view, B and D, which are dorsal views, and C, which is a posterior view. (See text for details.)

dividual $\mathrm{Clo}^{\mathrm{m} 39+}$ and $\mathrm{Clo}^{\mathrm{m} 39-}$ haploids were generated and genotyped. The SCL SSLP randomly segregated between the wild-type and mutant haploids, thus excluding $S C L$ as a candidate gene for clo. When an AB/DAR mapping panel was genotyped with this SSLP, the SCL locus was localized to linkage group 22 (Fig. 3E) of the Oregon zebrafish genetic map.

Forced expression of SCL in clo rescues both the hematopoietic and vascular defects

To determine whether $\mathrm{SCL}$ can rescue the clo defect, we expressed the full-length SCLa2.1 cDN A (cmv-SCLa2.1) in embryos microinjected at the one- to four-cell stage. Embryos were scored and fixed at $2 \mathrm{dpf}$, when GATA-1 (Fig. 4B) and tie-1 (Fig. 4E) transcripts are absent in $\mathrm{Clo}^{-1-}$ embryos, and flk-1 expression is undetectable in the head and trunk (mut, Fig. 4D). Because CMV promoter expression is unrestricted, cmv-SCLa2.1-injected embryos exhibit ectopic expression of $\mathrm{SCL}$ at high levels persisting into $2 \mathrm{dpf}$ (Fig. 4A).

For microinjection experiments, embryos were obtained from either adult clo heterozygote mating pai rs or

wild-type mating pairs as control. The embryos were scored at $2 \mathrm{dpf}$, separated with re spect to wild-type or mutant enlarged heart phenotype, and fixed for in situ analysis. SCL forced expression in embryos had no effect on normal development (Fig. 4A). When SCL is expressed in $\mathrm{Clo}^{-1-}$ embryos, red blood cells are evident in the trunk of the live $2 \mathrm{dpf}$ embryos, whereas none are seen in the uninjected $\mathrm{ClO}^{-1-}$ (data not shown). These red cells are better demonstrated by in situ for GATA-1 (Fig. 4B). Alternatively, o-dianisidine staining for complexed hemoglobin specifically demonstrates differentiated erythrocytes in the clo wild type and rescued $\mathrm{ClO}^{-1-}$ embryos (Fig. 4C). The number of red cells rescued by injection appears to be lower than that observed in uninjected clo wild-type embryos, suggesting that the rescue of hematopoietic defect is incomplete. SCL expression al so rescued the expression of flk-1 and tie-1 in the injected $\mathrm{Clo}^{-1-}$ embryos (Fig. 4D,E). The rescue of flk-1 expression in the cranial (Fig. 4D, arrowhead in $\mathrm{rsc} 1, \mathrm{rsc}$ ) and trunk vasculature (Fig. 4D, arrow with asterisks in rsc2) is mosaic among the injected embryos, and near complete rescues have been observed. Rescue of tie-1 expression is partial and is restricted to vasculature of the posterior tail (Fig. 4E, arrowhead). The pattern of tie-1 expression in the rescued $\mathrm{Clo}^{-1-}$ embryos also appears disorganized, lacking discrete sprouting of intersomitic vessels that are present in clo wild type (compare rSc and wt in Fig. 4E). Of the 502 embryos (381 $\mathrm{Clo}^{+1-}, 121 \mathrm{clo}^{-1}-$ injected with cmv-SCLa2.1 and analyzed by RNA in situ for molecular rescue, $42 / 121$ were rescued (35\%). Of the 473 uninjected embryos (349 $\mathrm{ClO}^{+/-}, 124 \mathrm{ClO}^{-1-}$ ) similarly analyzed, none were rescued. Control injection of cmv-GFP into 75 embryos ( $55 \mathrm{Clo}^{+1-}, 21 \mathrm{clo}^{-1}$ ) also failed to rescue the molecular markers in the mutants. Collectively, these experiments suggest that $\mathrm{SCL}$ acts downstream of clo to specify hematopoietic and angioblasts precursor formation.

\section{Discussion}

We found that SCL is expressed in early hematopoietic and vascular progenitors during normal development and is nearly absent in the clo mutant. Genetic analysis demonstrates that SCL is not linked to clo. In the $2 \mathrm{dpf}$ clo mutant embryos, GATA-1 and tie-1 transcripts are not detected; flk-1 is expressed only in a small number of cells in the posterior tail (Liao et al. 1997) but is absent in the head and mid-trunk. $\mathrm{Clo}^{-1-}$ embryos fail to initiate normal hematopoiesis and vascul ogenesis (Stai nier et al. 1995; Liao et al. 1997). When SCL is expressed in the $\mathrm{Clo}^{-1-}$ embryo, expression of GATA-1, flk-1, and tie-1 are restored at $2 \mathrm{dpf}$. However, the rescue is incomplete, perhaps because of mosai cism of the injected embryos. It is also possible that the clo defect cannot be entirely 


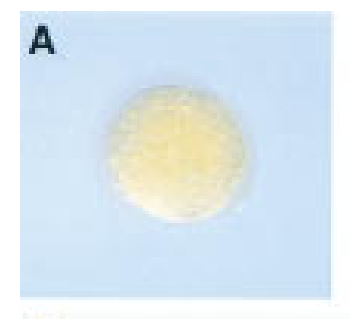

E

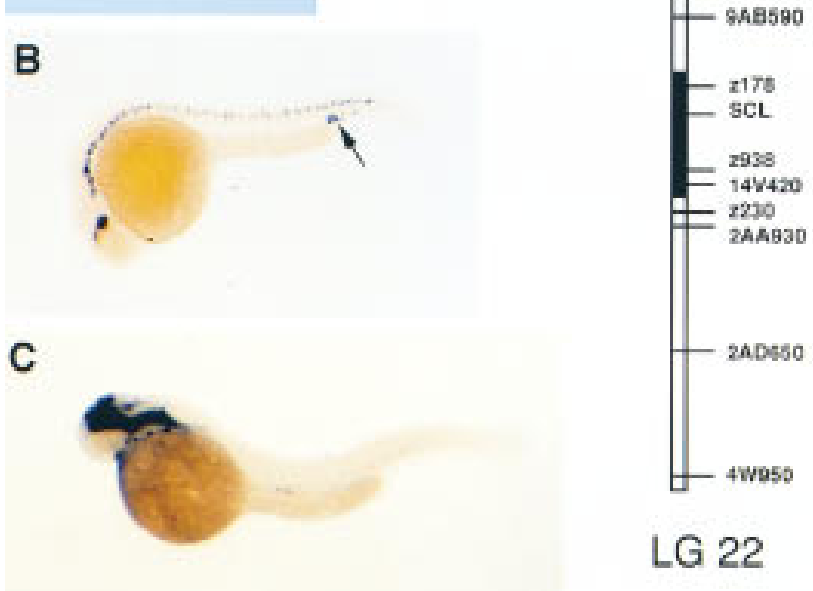

D
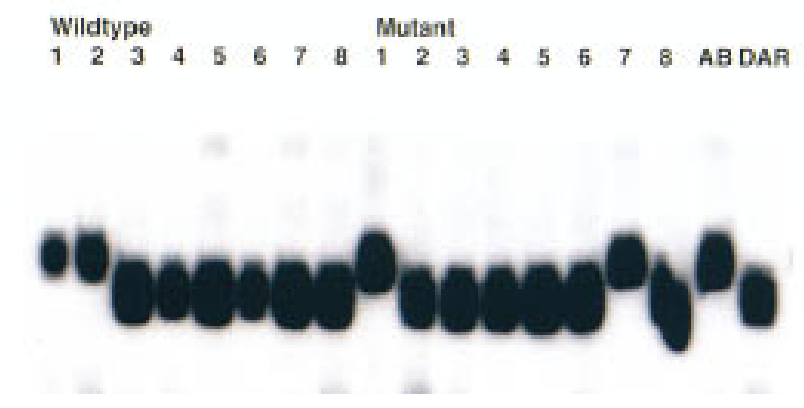

Figure 3. The zebrafish clo mutation affects SCL expression in hematopoietic and vascular tissues. SCL RNA in situ hybridization at 5-somite stage (A), $24 \mathrm{hpf}(\mathrm{B})$, and $2 \mathrm{dpf}(\mathrm{C})$. SSLP is defined in the $3^{\prime}$ UTR of the SCL CDNA and is unlinked to clo (D). SCL maps to the centromere of linkage group $22(\mathrm{E})$.

compensated by SCL expression, precluding a compl ete rescue.

These results suggest that SCL acts downstream of the clo defect and upstream of flk-1, GATA-1, and tie-1 to specify hematopoietic and vascular differentiation (Fig. 5). In the clo mutant, SCL, flk-1, and GATA-1 can be detected in a very small number of cells, and tie-1 is never detected. Interestingly, those few cells expressing $\mathrm{SCL}$, flk-1, and GATA-1 in $\mathrm{Clo}^{-1-}$ are all restricted to the posterior tail of zebrafish, a site that is devel opmentally anal ogous to the yolk sac of higher vertebrates, where primitive hematopoiesis occurs (for review, see Zon 1995). In the yolk sac of SCL ${ }^{-1-}$ mouse, flk-1 can be detected by RT-PCR at level s comparable to wild type, and tie-1 transcript level is reduced twofold (Visvader et al. 1998). Similarly, embryoid bodies derived from in vitro differentiation of ES cells demonstrate flk-1 expression
(Elefanty et al. 1997). However, analysis of flk-1 and tie-1 expression in the embryo proper of $\mathrm{SCL}^{-1-}$ mouse has not been performed. Hence, the epistatic relationship between SCL and flk- 1 in the context of the mouse embryo remains unclear. Our rescue of $\mathrm{flk}-\mathrm{l}$ expression in the $\mathrm{ClO}^{-1-}$ mutant suggests that $\mathrm{SCL}$ acts upstream or in parallel to flk- 1 in the zebrafish embryo.

Analysis of SCL expression during embryogenesis al so provides insight into how the hematopoietic and vascular tissues may be specified. In the posterior ICM, SCL, LMO-2, and GATA-2 are expressed, but not GATA-1 (Detrich et al. 1995; M.A. Thompson and L. Zon, unpubl.). In mice, GATA-2 is involved in hematopoietic progenitor proliferation (T sai et al. 1994), LMO-2 in blood progenitor differentiation (Warren et al . 1994), and GATA-1 in erythroid differentiation (for review, see Shivdasani and Orkin 1996). M orphologi cally, the hematopoi etic cells in the posteri or ICM are less differentiated than those of the anterior ICM (Detrich et al . 1995). Collectively, these results suggest that the posterior ICM hematopoietic cells represent a population of hematopoietic progenitors. Although most SCL-positive blood cells of the ICM enter circulation, we bel ieve some SCLpositive progenitors remain in the posterior ICM. The posterior ICM contributes to form the VVR of the posterior tail. M ore anteriorly, SCL expression is detected in dorsal bilateral stripes at $24 \mathrm{hpf}$. These SCL-positive cells migrate toward the trunk midline as development progresses. Preliminary studies suggest that these cells colonize the AGM (aorta-gonad-mesonephros) region, a site of definitive hematopoiesis in vertebrates (M.A. Thompson and L. Zon, unpubl.). At $4 \mathrm{dpf}, \mathrm{SCL}$ and Cmyb are coexpressed at high levels in the VVR. In mice, c-myb is associated with definitive hematopoiesis ( $\mathrm{Mu}$ censki et al. 1991). We propose that the VVR represents a larval site of definitive hematopoiesis in zebrafish. AGM formation (at $36 \mathrm{hpf}$ ) precedes that of the VVR (4 dpf), and we believe both regi ons form niches for definitive blood. The relative contribution of VVR and AGM to definitive blood remains to be elucidated by detailed transplantation and cell lineage studies.

Our data also support the notion of angiobl ast heterogeneity. We find SCL expressed in cranial angioblasts and in the ICM but not in precardiac angioblasts that contribute to the endocardium. The ICM has been implicated to contain angioblast potential (Pardanaud et al. 1996), and may be involved in forming the dorsal aorta and axial vein of the trunk and tail. The lack of SCL transcripts in the precardiac angioblasts suggests a molecular difference in the developmental programs that specify different vascular structures.

Our experiments suggest an instructive role for $\mathrm{SCL}$ in specifying both hematopoietic and vascular progenitors during zebrafish embryogenesis. Recent evidence from Xenopus animal cap assays suggests that $S C L$ is sufficient to specify the hematopoietic mesoderm (P. M ead and L. Zon, unpubl.). The dual role of SCL acting in hematopoiesis and yolk sac vitelline vessel angiogenesis has also been implicated by mouse chimera and transgenic studies (Visvader et al. 1998). These lines of evi- 
A

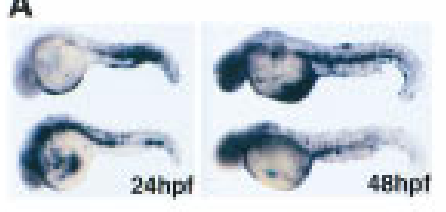

B

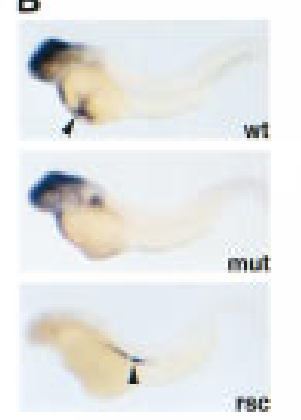

C

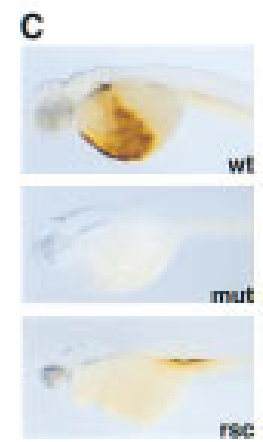

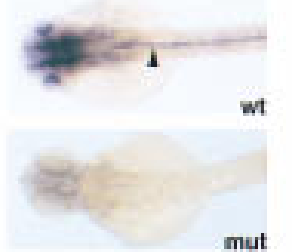

$\mathbf{E}$

mut

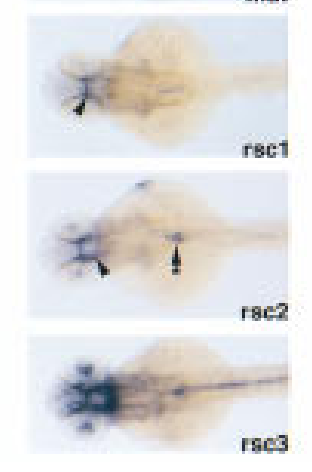

Figure 4. Forced expression of SCL rescues both the hematopoietic and vascular defects in clo. Microinjection rescue of $\mathrm{ClO}^{-1-}$ embryos with $\mathrm{Cmv}-\mathrm{SCL}$ 2.1. Embryos are shown in lateral views in $A-C$, dorsal views in $D$, and lateral close-ups of posterior tail in E. (A) SCL in situ hybridizations of injected embryos at 24 and 48 hpf; (B) GATA-1 in situ hybridization; (C) o-dianisine staining; (D) flk-1 and (E) tie-1 in situ hybridization. Wild-type clo (wt), mutant $\mathrm{CLO}^{-1-}$ (mut), and rescued $\mathrm{Clo}^{-1-}$ (rsc) are shown, all staged at $2 \mathrm{dpf}$. (See text for details.)

dence corroborate that SCL has an important dual function during vertebrate embryogenesis in blood and vascular development. This adds SCL to a growing list of bHLH transcription factors that have key roles in organogenesis, such as $\mathrm{N}$ euroD ( $\mathrm{N}$ aya 1997) and $\mathrm{M}$ yoD (for

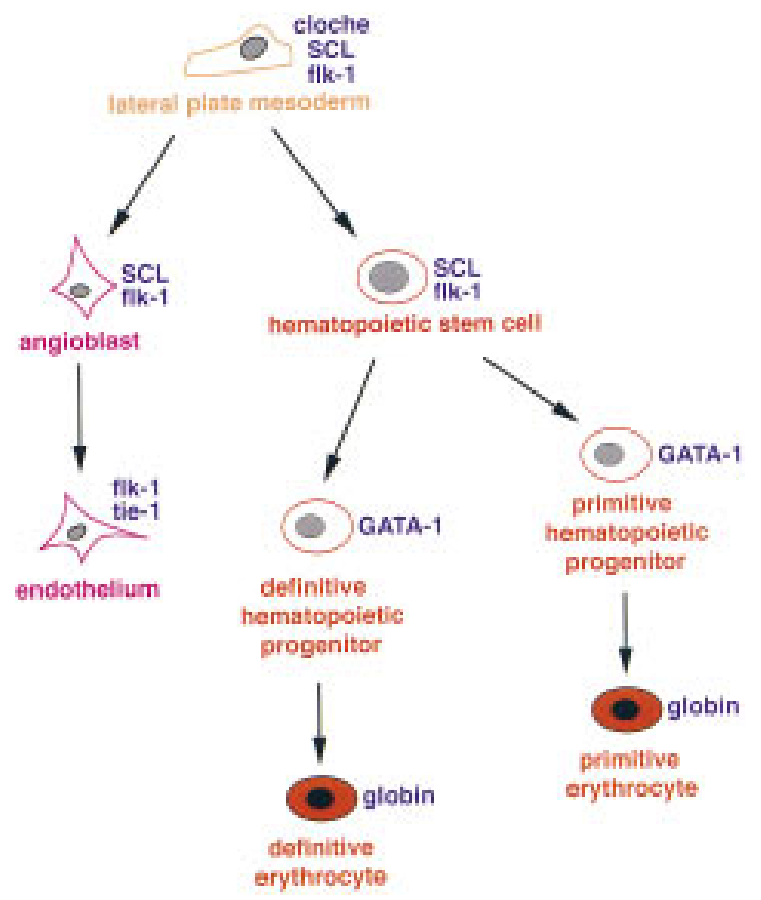

Figure 5. Proposed model of SCL function during hematopoiesis and vasculogenesis.

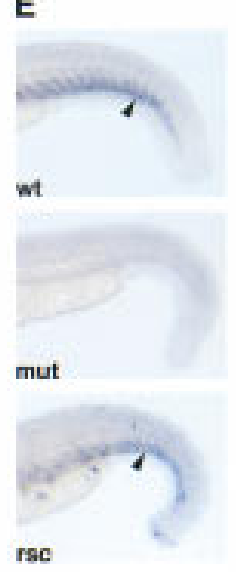

review, see Olson 1990), in pancreas and muscle formation, respectively.

\section{Materials and methods}

Zebrafish strains and maintenance

Zebrafish were maintained as described (Westerfield 1993), and staged as described (Kimmel et al. 1995). Embryos raised to time points beyond 24 hpf were treated with $0.003 \%$ phenylthiourea (PTU) to prevent mel anization (Sigma). The spontaneous clo allele, $\mathrm{clo}^{\mathrm{m} 39}$ (Stainier et al. 1995), was obtained from Mark Fishman, MGH (Charlestown). The clom39 allele was outcrossed to the standard wild-type strain (AB) for two generations. Heterozygotes carrying $A B \mathrm{Clo}^{\mathrm{m} 39}$ allele were crossed to a wild-type strain in the isogenic DAR genetic background to generate a AB/DAR mapping strain. Embryos used for in situ and microinjection experiments were collected from pairwise matings between identified $\mathrm{Clo}^{\mathrm{m} 39}$ heterozygotes. Haploids used for linkage analysis were generated essentially as described (Westerfield 1993).

\section{Isolation of zebrafish SCL CDNA}

Full-length zebrafish SCL CDNA was isolated by low stringency hybridization using the bHLH domain of mouse and Xenopus SCL as the labeled probe. The SCL bHLH fragments were generated by PCR with the following primers: murine $S C L$ (5'-TTCTTTGGGGAACCGGATG, 3'-CTCCTCCTGGTCATTGAG), Xenopus SCL (5'-TTTGGTGACCCAGACACC, and 3'-ATCGAGAAGTTTGGCAAG). An adult zebrafish kidney CDN A library (provided by J. Rast, Children's Hospital, St. Petersburg, FL) was screened, and one fulllength clone (SCLa2.1) was sequenced (DN A Sequencing Core Facility, Children's Hospital, Boston) and used in the experiments described herein (GenBank accession no. AF045432). Sequence analysis using BLAST, BESTFIT, and PILEUP programs was done with the UWGCG software package. Peptide sequence al ignment was done with Gene Inspector (Textco).

In situ hybridization, o-dianisidine staining, and histological analysis In situ hybridization and riboprobe synthesis were performed as described (Schulte-Merker et al. 1992), with modifications: Proteinase K digestion was extended to $2 \mathrm{~min}$ in $20 \mu \mathrm{g} / \mathrm{ml}$, and hybridization steps were carried out at $65^{\circ} \mathrm{C}$. The GATA-1 (Detrich et al. 1995), flk-1, and tie-1 (M.A. Thompson and L. Zon, pers. comm.) probes were prepared as described previously. o-Dianisidine staining was done as described (Detrich et al. 1995). Embryos for histological sections were treated with acetone and embedded in epon-aral dite (Polysciences, Inc.) plastic resin, for histological sections. Sections of $6 \mu \mathrm{m}$ were cut on LKB microtome and counterstained with $0.5 \%$ eosin, as described (Hyatt et al. 1996).

Mapping of SCL and polymorphism analysis in clo A SSLP was amplified with the following primers [forward, GGGATTCAGCAGCCCTATC; reverse primer, GCAGGGCTAAAGTTGGGGT (T/G)]. The 190-bp (AB) or 188-bp (DAR) product was resolved on $8 \%$ denaturing urea-polyacrylamide gel. This SSLP was used to type $\mathrm{Clo}^{\mathrm{m} 39^{+}}$and $\mathrm{Clo}^{\mathrm{m} 39^{-}}$haploid individuals, and 96 individuals of a diploid AB/DAR map panel (. Postlethwait).

\section{CDNA expression constructs and microinjection}

The SCLa2.1 full-length CDNA defined by BamHI and Xhol sites was subcloned into BamHI and Xhol sites of the $\mathrm{pCS2}^{+}$vector, containing the CMV promoter [D. Turner (Fred Hutchinson Cancer Research Center, Seattle, WA) and R. Rupp (Friedrich-M iescher Laboratorium, Tübingen, Germany)]. The injection construct (cmv-SCLa2.1) plasmid DNA was diluted to $100 \mathrm{ng} / \mu \mathrm{l}$ in sterile $\mathrm{ddH}_{2} \mathrm{O}$. A control plasmid (cmv-GFP) was constructed with the green fluorescent protein (B. Seed, M GH, Boston), gene inserted into Clal and $\mathrm{Xbal}$ sites of the $\mathrm{pCS} 2^{+}$vector, and diluted to $125 \mathrm{ng} / \mu \mathrm{l}$. Microinjection was performed essentially as described (Westerfield 1993), utilizing $\mathrm{N}$ ikon picoinjector and $\mathrm{N}$ arishige micromanipulator. 


\section{Acknowledgments}

We thank Stuart Orkin, Paul M ead, Catherine Procher, David Ransom, and Ramesh Shivdasani for critical review of this manuscript; Ellen Schmitt for technical assistance with histological sections; and John Dowling for the use of histol ogical reagents and microtome instruments. This work was funded by National Institutes of Health grant P50 DK 49216-03. E.C.L. is supported by the $\mathrm{N}$ ational Eye Institute Research Program in Molecular A pproaches to Vision (grant 5 T32 EY 077110-10), Division of Health Sciences and Technology/MIT research funding for medical students, and A merican Cancer Society Stone Fel lowship award. B.H.P. is supported by Howard Hughes Postdoctoral Fellowship for Physicians. A.C.O. is a recipient of Anti-Cancer Victoria Postgraduate Research Scholarship. L.I.Z. is an Associate Investigator of the Howard Hughes Medical Institute.

The publication costs of this article were defrayed in part by payment of page charges. This article must therefore be hereby marked "advertisement" in accordance with 18 USC section 1734 sol ely to indicate this fact.

\section{References}

Begley, C.G., P.D. Aplan, M.P. Davey, K. Nakahara, K. Tchorz, J Kurtzberg, M.S. Hershfield, B.F. Haynes, D.I. Cohen, T.A. Waldman, and I.R. Kirsch. 1989. Chromosomal translocation in human leukemic stem-cell line disrupts the $\mathrm{T}$-cell receptor delta-chain diversity region and results in a previously unreported fusion transcript. Proc. Natl. Acad. Sci. 86: 2031-2035.

Bernex, F., P. De Sepulveda, C. Kress, C. Elbaz, C. Delouis, and J.-J. Panthier. 1996. Spatial and temporal patterns of c-kit-expressing cells in the WlacZ/+ and Wlacz/Wlacz mouse embryos. Development 122: 3023-3033.

Chen, Q., C.Y. Yang, J.T. Tsan, Y. Xia, Y., A.H. Ragab, S.C. Peiper, A. Carroll, and R. Baer. 1990. Coding sequences of the tal-1 gene are disrupted by chromosome transl ocation in human $\mathrm{T}$ cell leukemia. J. Exp. Med. 172: 1403-1408.

Detrich, H.W., M.W. Kieran, F.-Y. Chan, L.M. Barone, K. Yee, J.A. Rundstadler, S. Pratt, D. Ransom, and L.I. Zon. 1995. Intraembryonic he matopoi etic cell migration during vertebrate devel opment. Proc. Nat. Acad. Sci. 92: 10713-10717.

Drake, C.J., S.J. Brandt, T.C. Trusk, and C.D. Little. 1997. Tal1/SCL is expressed in endothelial progenitor cells/angioblasts and defines a dorsal-to-ventral gradient of vasculogenesis. Dev. Biol. 192: 17-30.

El efanty, A.G., L. Robb, R. Birner, and C.G. Begley. 1997. Hematopoi eticspecific genes are not induced during in vitro differentiation of sclnull embryonic stem cells. Blood 90: 1435-1447.

Finger, L.R., J. Kagan, G. Christopher, J. Kurtzberg, M.S. Hershfield, P.C. N owell, and C.M. Croce. 1989. Involvement of the TCL5 gene on human chromosome 1 in $\mathrm{T}$-cell leukemia and melanoma. Proc. Natl. Acad. Sci. 86: 5039-5043.

Fouquet, B., B. Weinstein, F.C. Serluca, and M.C. Fishman. 1997. Vessel patterning in the embryo of the zebrafish: Guidance by notochord. Dev. Biol. 183: 37-48.

Green, A.R., E. Salvaris, and C.G. Begley. 1991. Erythroid expression of the "helix-loop-helix" gene, SCL. Oncogene 6: 475-479.

Green, A.R., T. Lints, J. Visvader, R. Harvey, and C.G. Begley. 1992. SCL is coexpressed with GATA-1 in hemopoietic cells but is also expressed in developing brain. Oncogene 7: 653-660.

Green, T. 1996. M aster regulator unmasked. Nature 383: 575-577.

Hyatt, G.A., E.A. Schmitt, N. Marsh-Armstrong, P. M cCaffery, U.C. Drager, and J.E. Dowling. 1996. Retinoic acid establishes ventral retinal characteristics. Development 122: 195-204.

Kabrun, N., H.-J. Buhring, K. Choi, A. Ullrich, W. Risau, and G. Keller. 1997. Flk-1 expression defines a population of early embryonic he matopoietic precursors. Development 124: 2039-2048.

Kallianpur, A.R., J.E. Jordan, and S.J. Brandt. 1994. The SCL/TAL-1 gene is expressed in progenitors of both the hematopoietic and vascular systems during embryogenesis. Blood 83: 1200-1208.

Kimmel, C.B., W.W. Ballard, S.R. Kimmel, B. Ullmann, and T.F. Schilling. 1995. Stages of embryonic development of the zebrafish. Dev. Dynam. 203: 253-310.

Liao, W., B.W. Bisgrove, H. Sawyer, B. Hug, B. Bell, K. Peters, D.J. Grunwald, and D.Y.R. Stainier. 1997. The zebrafish gene cloche acts up- stream of a flk-1 homologue to regulate endothelial differentiation. Development 124: 381-389.

Mucenski, M.L., K. McLain, A.B. Kier, S.H. Swerdlow, C.M. Schreiner, T.A. Miller, D.W. Pietryga, W.J. Scott, and S.S. Potter. 1991. A functional c-myb gene is required for normal murine fetal hepatic hematopoiesis. Cell 65: 677-689.

Mustonen, T. and K. Alitalo. 1995. Endothelial receptor tyrosine kinases involved in angiogenesis. J. Cell. Biol. 129: 895-898.

N aya, F.J., H.P. Huang, Y. Qiu, H. Mutoh, F.J. DeM ayo, A.B. Leiter, and M.J. Tsai. 1997. Diabetes, defective pancreatic morphogenesis, and abnormal enteroendocrine differentiation in BETA2/neuroD-deficient mice. Genes \& Dev. 15: 2323-2334.

Okuda, T., J. van Deursen, S.W. Hiebert, G. Grosveld, and J.R. Downing. 1996. AML1, the target of multiple chromosomal translocations in human leukemia, is essential for normal fetal liver hematopoiesis. Cell 84: 321-330.

Olson, E.N . 1990. M yoD family: A paradigm for development? Genes \& Dev. 4: 1454-1461.

Pardanaud, L., C. Altmann, P. Kitos, F. Dieterlen-Lievre, and C.A. Buck. 1987. Vasculogenesis in the early quail blastodisc as studied with a monoclonal antibody recognizing endothelial cells. Development 100: 339-349.

Pardanaud, L., D. Luton, M. Prigent, L.-M. Bourcheix, M. Catala, and F. Dierterlen-Lievre. 1996. Two distinct endothelial lineages in ontogeny, one of them related to hemopoiesis. Development 122: 13631371.

Sabin, F.R. 1920. Studies on the origin of blood vessels and of red blood corpuscles as seen in the living blastoderm of chicks during the second day of incubation. Contrib. Embryol. 9: 213-262.

Schulte-Merker, S., R.K. Ho, B.G. Hermann, and C. N üsslein-Volhard. 1992. The protein product of the zebrafish homol ogue of the mouse $T$ gene is expressed in nuclei of the germ ring and the notochord of the early embryo. Development 116: 1021-1032.

Shal aby, F., J. Rossant, T.P. Yamaguchi, M. Gertsenstein, X.-F. Wu, M .L. Breitman, and A.C. Schuh. 1995. Failure of blood-island formation and vasculogenesis in Flk-1 deficient mice. Nature 376: 62-66.

Shalaby, F., J. Ho, W., K-D. Stanford, A. Schuch, L. Schwartz, A. Bernstein, and J. Rossant. 1997. A requirement for Flk1 in primitive and definitive hematopoiesis and vasculogenesis. Cell 89: 981-990.

Shivdasani, R.A. and S.H. Orkin. 1996. The transcriptional control of hematopoiesis. Blood 87: 4025-5039.

Stainier, D.Y., R.K. Lee, and M.C. Fishman. 1993. Cardiovascular development in the zebrafish. Development 119: 31-40.

Stainier, D.Y.R., B.M. Weinstein, H.W. Deitrich III, L.I. Zon, and M.C. Fishman. 1995. cloche, an early acting zebrafish gene, is required by both the endothelial and hematopoietic lineages. Development 121: 3141-3150.

Tsai, F.-Y., G. Keller, F.C. Kuo, M. Weiss, J. Chen, M. Rosenblatt, F.W. Alt, and S.H. Orkin. 1994. An early hematopoietic defect in mice lacking the transcription factor GATA-2. Nature 371: 221-226.

Visvader, J.E., Y. Fuji wara, and S.H. Orkin. 1998. U nsuspected role for the T-cell leukemia protein SCL/tal-1 in vascular devel opment. Genes \& Dev. 12: 473-479.

Wang, Q., T. Stacy, J.D. Miller, A.F. Lewis, T.-L. Gu, X. Huang, J.H. Bushweller, J.-C. Bories, F. Alf, G. Ryan, P.P. Liu, A. Wynshaw-Boris, M. Binder, M. M arin-Padilla, A.H. Sharpe, and N.A. Speck. 1996. The $\mathrm{CBF} \beta$ subunit is essential for CBFa2 (AML1) function in vivo. Cell 87: 697-708.

Warren, A.J., W.H. Colledge, M.B.L. Carlton, M.J. Evans, A.J.H. Smith, and T.H. Rabbitts. 1994. The oncogenic cysteine-rich LIM domain protein Rbtn2 is essential for erythroid development. Cell 78: 45-57.

Westerfield, M. 1993. The zebrafish book: A guide for the laboratory use of zebrafish (Brachydanio rerio). University of Oregon Press, Eugene, OR.

Wood, H.B., G. May, L. Healy, T. Enver, and G.M. Morriss-Kay. 1997. CD34 expression patterns during early mouse development are re lated to modes of blood vessel formation and reveal additional sites of hematopoiesis. Blood 90: 2300-2311.

Yamaguchi, T.P., D.J. Dumont, R.A. Conlon, M.L. Breitman, and J. Rossant. 1993. flk-1, an flt-related receptor tyrosine kinase is an early marker for endothelial cell precursors. Development 118: 489-498.

Zon, L.I. 1995. Developmental biology of hematopoiesis. Blood 86: 28762891. 


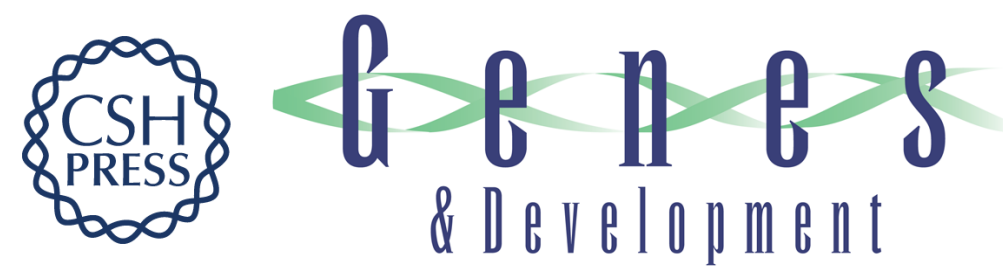

\section{SCL/Tal-1 transcription factor acts downstream of cloche to specify hematopoietic and vascular progenitors in zebrafish}

Eric C. Liao, Barry H. Paw, Andrew C. Oates, et al.

Genes Dev. 1998, 12:

References This article cites 37 articles, 22 of which can be accessed free at: http://genesdev.cshlp.org/content/12/5/621.full.html\#ref-list-1

License Email Alerting
Service $\begin{aligned} & \text { Receive free email alerts when new articles cite this article - sign up in the box at the top } \\ & \text { right corner of the article or click here. }\end{aligned}$

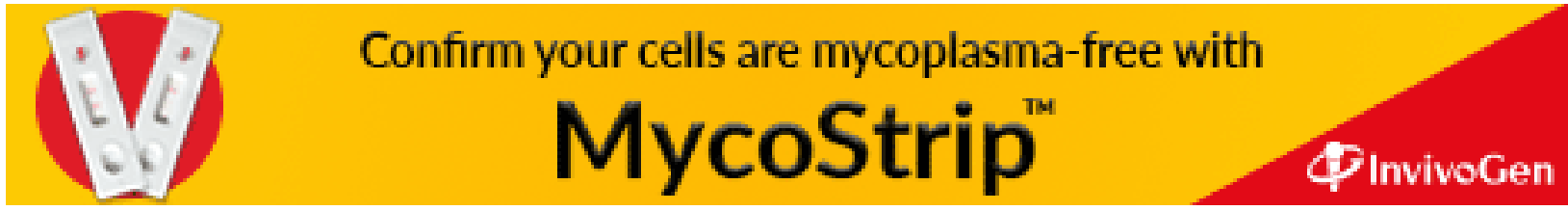

